\title{
OKUL ÖNCESİ DÖNEMDE TIRNAK KOPARMA DAVRANIŞINA YAKLAŞIM: OLGU SUNUMU
}

\author{
NAIL BITING IN PRESCHOOL: A CASE REPORT
}

\author{
Melike METE*, Aylin YETIM**, Gülbin GÖKÇAY***, Behiye ALYANAK***
}

\begin{abstract}
ÖZET
Tırnak koparma çocukluk çağında sık rastlanan bir davranış bozukluğudur. Ciddi anksiyete bozukluğundan kaynaklanabilen bu durum duygusal ve/veya fiziksel istismar sonucu ortaya çıkabilir. Tırnak koparma sorunu çocuk ruh ve beden sağlığını birçok yönden olumsuz etkiler. Ağır olgularda, diş kökü hasarı, maloklüzyon, çene bozuklukları ve parazitoz gelişebilir. Tedavide farklı yaklaşımlar uygulanabilir. Dört yaş dokuz aylık erkek olgunun Sosyal Pediyatri Polikliniğinde yapılan rutin kontrolü sırasında ebeveyni tarafından tırnak koparma davranışının olduğu belirtildi. Muayene bulgularında özellik saptanmayan olgu ve ailesi Çocuk Gelişimi ve Eğitimi uzmanına yönlendirildi. Çeşitli gelişim testleri ile yaşına uygun gelişim düzeyinde olduğu belirlenen olgunun öyküsünde bir y1l önce annesi tarafindan uygulanan sözel ve şüpheli fiziksel şiddet sonrası çocukta tırnak koparma davranışının başladığı öğrenildi. Kendisi, ebeveyni ve kardeşi ile ayrı ayrı görüşmeler yapılan olgunun bu davranışının anksiyete nedeniyle ortaya çıktığı belirlenerek davranış terapisi uygulanmaya başlandı. Aile görüşmelerinde annenin ve diğer aile bireylerinin olguya yaklaşım modeli düzenlendi. Dört ay süren izlem sonucunda olguda tırnak koparma davranışı geriledi ve aile bireylerinin davranış modelleri düzeltildi. Çocuk sağlığı izlemlerinde tırnak koparma davranışı çocuk ruh sağlığ1 açısından dikkatle ele alınması gereken bir konudur. Tedavi yaklaşımında düzenli davranış terapisi ve aile ile işbirliği yapılması önemlidir.
\end{abstract}

Anahtar kelimeler: Tırnak koparma davranış1; okul öncesi dönem; anksiyete bozukluğu; davranış terapisi

\begin{abstract}
Nail biting behavior is a common problem in childhood. Nail biting behavior which is associated with severe anxiety disorders may occur as a result of emotional and/or physical abuse. This behavior problem has negative effects on physical and psychological health of children. Tooth root damage, malocclusion, jaw disorders and parasitosis may develop in severe cases. There are controversial approaches for the treatment. The nail biting behavior of a 57-monthold boy was issued by his parent during the well-child visit. There was no pathological sign in the examination of the patient, who later was directed to the Child Development and Education specialist. His development was already evaluated as age-appropriate with various developmental screening tests during his previous controls. In the patient's detailed history, it was ascertained that the nail biting behavior has developed after the verbal and potential physical violence that had been applied by his mother one year ago. Knowing the fact that this behavior was an anxiety linked disorder, several meetings had been carried out separately with the mother, the child and his brother. While behavioral therapy was being applied to the patient, approach model of the mother and other family members were schematized in the interviews. After a four month-follow-up period, it was observed that the nail biting behavior has decreased and the behavior model of the family had been corrected. Nail biting behavior should be considered and evaluated carefully in terms of children's mental health. Regular behavioral therapies and cooperation with the family members are important in the management of these cases.
\end{abstract}

Key words: Nail biting behavior; preschool; anxiety disorder; behavioral therapy

Date received/Dergiye geldiği tarih: 01.11.2015 - Date accepted/Dergiye kabul edildiği tarih: 01.02.2016

* İstanbul Üniversitesi, Çocuk Sağlı̆̆ı Enstitüsü Ana Çocuk Sağlı̆̆ı Programı,

** İstanbul Tıp Fakültesi, Çocuk Sağlığı ve Hastalıkları Anabilim Dalı, *** Çocuk ve Ergen Ruh Sağlığı ve Hastalıkları Anabilim Dalı, İstanbul, TÜRKIYYE

(Corresponding author/İletişim kurulacak yazar: melikemt@gmail.com) 


\section{GíRiş}

Tırnak koparma davranışı (TKD) özellikle çocukluk döneminde sık rastlanmakta olan, erişkin dönemde de çeşitli psikolojik bozukluklarla beraber görülebilen bir durumdur. Tırnak koparma davranışının genellikle anksiyete ya da duygusal gerginlik ile ilişkili olduğu varsayılır; ancak bu konuda yeterli araştırma bulunmamaktadır (1). Obsesif kompulsif bozukluk, dikkat eksikliği ve hiperaktivite bozukluğu, Tourette Sendromu gibi hastalıkların bulgusu olarak da karşımıza çıabilmektedir. Psikiyatride tırnak koparma davranışına ilişkin tartışmalı yaklaşımlar bulunmaktadır. Genellikle davranış terapisi ile tedavi edilen tırnak koparma davranışı diş kökü hasarı, maloklüzyon, çene bozuklukları ve parazitoz gibi hastalıklara da zemin hazırlayarak çocuk sağlığını birçok alanda olumsuz etkileyebilmektedir (2).

$\mathrm{Bu}$ yazıda rutin kontrolü sırasında tırnak koparma davranış1 olduğu belirlenen olgunun bu davranışına yol açan sebepler irdelendi ve olguya bütüncül yaklaşım tartışıldı.

\section{OLGU}

İstanbul Tıp Fakültesi Sosyal Pediyatri Bilim Dalı (BD) polikliniğine rutin kontrolü nedeniyle başvurusunda, bir süreden itibaren TKD geliştiği öğrenilen 4 yaş 9 aylık erkek olgu, değerlendirme, takip ve tedavi amaciyla Çocuk Gelişimi ve Eğitimi uzmanına yönlendirildi. Öyküsünde bir yıl önce parkta oyun oynadığı sırada annesi çocuğunun kaybolduğunu düşünerek yüksek endişeyle olguya öfke ve şiddet ile bağırmış. Bu olay sonrasında olguda TKD başlamış. Bu davranış özellikle televizyon izlerken, bilgisayar oynarken ve heyecanlandığında artış göstermekteymiş.

Erken term olarak hastanede normal spontan doğum ile doğan olgu düzenli olarak Sosyal Pediyatri BD polikliniğinde takip edilmekteydi. Beslenme öyküsünde özellik olmayan olgunun geçirilmiş ciddi hastalık öyküsü ya da kronik hastalığ 1 yoktu. Rutin izlemde kullanılan Gelişimi İzleme ve Destekleme Rehberi, Sosyal İletişim Alan Tarama Testi, Değiştirilmiş Erken Çocukluk Dönemi Otizm Tarama Ölçeği (Modified Checklist for Autism in Toddlers) gibi testleri ve nörolojik değerlendirmeleri normal idi. Anne, baba ve bir erkek kardeşi ile yaşamakta olan olgunun soygeçmişinde herhangi bir hastalık öyküsü olmadığı ve ailede başka TKD olan bireyin bulunmadığı öğrenildi.

\section{Çocuk Gelişimi Uzmanının Değerlendirmesi}

Anneden yalnız alınan öyküye göre olgu ebeveynler için plansız bir bebekti. Anne her iki bebeğini de kolay kabullendiğini, doğum sonrası annelik hüznü yaşadığını ancak bunun birkaç günde sonlandığını belirtti. Olgu 12 aylıktan beri kreşe gitmekteydi. Kendisinden 15 ay büyük olan ağabeyi anaokuluna gidiyordu. Anne hemşireydi ve nöbetleri yoktu. Olgu 12 aylık olduğunda izni bitmiş yeniden işe başlamıştı. Olgu annenin çalıştığı kurumun kreşine baştan beri tam zamanlı gidiyor, anne eve dönerken çocuklarını alıp eve geliyordu. Olgunun ağabeyi aynı kurumun kreşinin bir üst yaş grubuna devam ediyordu. Baba mühendis olarak çok yoğun çalıştığ 1 için ve genellikle eve geldiğinde çocuklar uyumuş olduğundan, hafta içi baba ile çocukların pek görüsşemediği belirtildi. Sadece sabah kahvaltıda ve bazı pazar günleri ailece vakit geçirebiliyorlardı. Evde çocuklarla ilgilenmek ve kuralları belirlemek annenin işi olarak görülmekte idi; baba çocuklara kural koymuyordu. Anne eşiyle arasında bu durumun problem yaratmadığı görüşündeydi ancak genel olarak çocuklar ile eşinin birlikte vakit geçirememelerinden şikayetçiydi. Anne ve baba çocukların bakımında tutum birliği içinde olarak değerlendirildi. Anne çocuklara "hayır" dediğinde baba müdahale etmiyor, sessiz kalmayı tercih ediyordu. Anne ve baba birlikte çocuklarla fazla zaman geçiremese de, anne günlük işlerde çocuklara odayı toplama, sofrayı kurmaya yardım etme gibi sorumluluklar veriyordu.

Öyküde olgunun bir yıl önce parkta oyun oynarken 10 dakika süreyle annesinin görüş alanından uzaklaştı̆̆ 1 , bunun üzerine annesinin onu endişe ile aradığ 1 ve bulduğunda bir daha yanından ayrılmaması için ona bağırdığı ve korkuttuğu öğrenildi. Bu olay sonrası olguda tırnak koparma davranışının başladığı belirlendi. Ailede başka tırnak koparma öyküsü olmadığını ve olgunun bu davranışı konusunda oldukça endişeli olduğunu belirten anne, oğlunu bu konuda sürekli uyardığını, acı oje sürerek bu davranışı durdurmaya çalıştı̆̆ını ancak buna rağmen davranışın devam ettiğini söyledi. Aile maddi ödüller ile de davranışı durdurmaya çalışmış ancak başarılı olamamış idi. Babanın bu durumu fazla önemsemediği anne tarafından belirtildi.

Olgunun öyküsünde belirlenen tırnak koparma davranışı parktaki olay sonrası yaşanan stres ve anksiyete ile başlamış, annenin tırnak koparmaması için sık sık uyarması ile pekişmişti. Anneye tırnak koparma davranışıla ilgili yapılan uyarıcı / baskıcı tutumun bırakılması, evde bu konuyla ilgili konuşulmaması, baba ile cocukların oyun oynaması ve ailece aktivite yapılması önerildi. Yaklaşımda ebeveynlere etkili ve olumlu anne-baba tutumları kazandırma hedeflendi.

Bir hafta sonra yapılan birinci seansta olgunun ruhsal değerlendirmesinde özellik saptanmadı. Kendini iyi ifade eden olgu ile karşılıklı iletişim rahat kuruldu. Birinci seanstan sonraki üç seansta yalnız görüşme yapıldı. Çocuğa tırnak koparmanın sağlık açısından olumsuz etkileri anlatıldı. Çocukla kolayca işbirliği içine girildi ve kendisinin de bu davranıştan kurtulmak istediği öğrenildi. Davranış kontrol çizelgesi (davranışsal ev ödevi) oluşturularak davranış terapisi uygulanmaya başlandı. Her günün bir kutucuğu vardı; gülen yüz (olumlu pekiştireç) ve üzülen yüz (olumsuz pekiştireç) çıkartmaları çocuğa verildi. Gün sonuna kadar tırnak koparma davranışını yapmazsa yıldız, kurdela vb. simgeler arasından seçtiği simgesel ödülü (gülen yüz), yaparsa olumsuz pekiştireci (üzülen yüz) annesinin yardımıyla çizelgesine yapıştırması istendi. Pekiştireçlerin gün sonunda kutucuğa yapıştırılması planlandı. Bu yaklaşımda olgunun etkin bir biçimde katılımı beklenir. Skinner'a göre edimsel koşullama pekiştireçlerin kullanıldığı bir koşullama tipidir. Pekiştireçlerin olumlu davranışların hemen sonrasında verilmesi gerekir. $\mathrm{Bu}$ durumda olumlu davranışın meydana gelme sıklığı artmaktadır (3).

On beş gün sonra yapılan ikinci seansta olgu ve anne görüşmeye geldi. Anne olgunun bu zaman süresince hiç 
tırnak koparmadığını söyledi. Çizelge kontrol edildi ve olgunun başarısı takdir edildi. Davranış terapisinin tek seansta olumlu sonuç verdiği görüldü. Çocukla görüşmeye yalnız devam edildi ve aile içi iletişimi, okul ilişkilerini irdelemek için 'Bir İnsan Çiz Testi' ve 'Aile Çiz Testi’ ile projektif çalışmalar yapıldı.

Uygulanan testler esnasında olgu kendiliğinden "Ağabeyim sünnet oldu benim de pipi mi kesecekler mi?" diye sordu. Bu soru görüşmelerde irdelendi. Kastrasyon anksiyetesi ile ilgili olgu ile konuşuldu, ancak bu kaygının ilk olarak babasının kuzenine kızdığı bir anda "Senin pipini keserim, yaramazlık yok" demesi ve amcasının da kendisine "Ben de senin pipini keserim, akıllı durun" demesi ile başladığı anlaşıldı.

Değerlendirmeler sona erdiğinde olguya tekrar davranış kontrol çizelgesini isteyip istemediği soruldu. Olgu çizelgeyi istemediğini, artık tırnak yemekten hoşlanmadığını belirtti. Olgunun isteği ile bireysel davranışçı terapi sonlandırıldı.

Değerlendirme sonucu çocuğun okulda stres kaynaklı anksiyete ve arkadaşları ile çatışma yaşamadığı, anneyi güçlü bulduğu ve anneyle özdeşime girdiği, ağabeyiyle rekabet içerisinde olduğu, babası ve ağabeyini daha yakın bulduğu, evde stres etkeni olduğu, kastrasyon anksiyetesi yaşadığı anlaşıldı.

Iki hafta sonra anne ile yalnız yapılan üçüncü seansta olguda saptanan kaygılar ve stres etkenleri değerlendirildi. Baba görüşmelere çağrıldı̆̆ gelmedi ancak bizim önerimiz doğrultusunda çocuklarıyla daha fazla zaman geçirmiş olduğu öğrenildi. Anneye babanın bu yaklaşımının devam etmesi gerektiği belirtildi. Olgunun ağabeyi ile çatışma yaşayıp yaşamadığı sorulduğunda, olgunun rekabeti sevdiğini ancak ağabeyine göre gelişiminin daha iyi olduğunu, ağabeyinin çok duygusal olduğunu, olgunun ağabeyine göre okulda daha başarılı olmasını beklediklerini ve bu yüzden 5 yaşında olmasına rağmen onu da ağabeyi gibi 1. sınıfa yazdırmak istedikleri öğrenildi. Anneye çocukların yanında bu gözlemlerinin sesli dille getirilmemesi gerektiği anlatıldı. Ayrıca olgunun 6 yaşında 1. sınıfa başlaması önerildi ancak anne bu konuda kararlı olduğunu belirtti. Ebeveynlerin olgudan yüksek akademik başarı beklentisi olduğu ve bundan dolayı olgu ile ağabeyi ile arasında yıkıcı rekabet algısının tetiklendiği anlaşıldı. Anneye olgu ile ağabeyinin aynı sınıfa verilmemesi önerildi.

Kastrasyon anksiyetesi irdelendiğinde; ağabeyin olgu doğmadan sünnet olduğu öğrenildi ve bu olayın olguyu etkilemediği ancak aile büyüklerinin sünneti evde cezalandırma yolu gibi sözel olarak kullandıkları belirlendi. Evde bu konuyla ilgili şaka yapılmaması, ceza ya da tehdit amaçlı bu konunun kullanılmaması gerektiği anlatıldı. Ayrıca olgu sünnet olmadan önce uzman desteği alınması önerildi.

Üç hafta sonra olgu ve ağabeyi ile birlikte yapılan dördüncü seansta birlikte aktivite yapıldı. Oynanan oyunda olgunun baskın olduğu, ağabeyini yönettiği, lider özellikleri taşıdığı gözlemlendi. Beşinci seans 2 hafta sonra anne ile yalnız yapıldı. Anne olgu ve ağabeyinin özel bir okulun sınavına girdiğini yalnızca olgunun başarılı olduğunu belirtti. Ağabeyinin öz güvenini yükseltmek için başarılı olduğu sanat alanlarının (resim, yaratıcılık) aile tarafindan ön plana çıkartılması ve drama, yüzme kursu gibi aktivitelere yönlendirilmesi önerildi.

Son görüşmeden yaklaşık 1 ay sonra yapılan altıncı seansta olgu ve annesi ile durum kontrol görüşmesi yapıldı. Annesi tarafından olgunun tırnak koparma davranışını yinelemediği, tatilde olan okulunun açıldığı ve okula isteyerek devam ettiği öğrenildi. Ancak ağabeyiyle zaman zaman oyun oynarken çatışma yaşadığı ve kurallara uyma konusunda zorluk yaşadığı bildirildi. Kreşte ise kurallara uyduğu, arkadaşları ile olumlu ilişkiler içerisinde olduğu öğrenildi. Olgu ile yalnız devam edilen seansta okul ve evdeki kurallarla ilgili görüşüldü. Anne ve çocuk ile ortak ev kuralları oluşturuldu.

Toplam üç ay süren görüşmeler sonucunda anneye yapılan yoğun aktarımı dengelemek için anneyle özdeşimi babaya yansitarak, baba rolünün belirginleşmesi sağlandı. Çocuğun kaygıları irdelendi ve bireysel, psikososyal gelişimi desteklendi. Tırnak koparma davranışını bırakması sağlanarak benlik saygısı arttırıldı. Olgunun akademik algısı rahatlatıldı ve ağabeyiyle yapıcı rekabet sağlamak için aile bilinçlendirildi. Ayrıca kastrasyon kaygısı azaltıldı.

\section{TARTISMA}

Tırnak koparma davranışı DSM-V'te spesifik bir tanı olarak yer almamaktadır ancak obsesif kompulsif bozukluk kategorisi altında beden odaklı yineleyici davranışlar bozukluğu olarak sınıflandırılabilir (4). Beden odaklı yineleyici davranışlar terimi deri toplama, saç çekme, tırnak koparma gibi yıkıcı, sorunlu ve görünüşte işlevsel olmayan davranışları ifade eder (1). Literatürde ekskoryasyon bozukluğu (deri soyma), trikotillomani (k1l yolma), patolojik tırnak koparma ve yanak ısırma davranışlarının beden odaklı yineleyici davranışlar bozukluğu ile ilişkisi belgelenmektedir (4). Tırnak koparma genellikle olumsuz sonuçlara sebep olmayan basit bir alışkanlık olarak kabul edilir. Ancak bu davranış sosyal problemlere, anlamlı doku ve tırnak hasarına yol açtığı zaman beden odaklı tekrarlayan davranışlar kategorisi içinde incelenmelidir (1). Synder ve Friman tırnak koparma ile ilgili literatürü gözden geçirmiş ve 4-6 yaş arasında tırnak koparma sıklığının arttığını, puberte döneminde zirveye ulaştı̆̆ını, \%25- 60 oranında değișen sıklığı olduğunu, geç ergenlik dönemi ile 35 yaş arasında tırnak koparma sıklığını \% 10-30 arasında, 35 yaşından sonra da \% 10'un altına düştüğünü rapor etmişlerdir.(1) Tırnak koparma davranışının genellikle anksiyete veya duygusal gerginlik ile ilişkili olduğu varsayılmaktadır fakat bu varsayım konusunda da araştırmalar yetersizdir (1). Olgumuzda bu davranışın gelişme aşamasında anne tarafindan uygulanan sözel ve şüpheli fiziksel şiddet sonrası çocuğun yaşadığı yoğun stres ve anksiyete durumu mevcuttu. Bu olaydan sonra çocukta tırnak koparma davranışı devam etmiş, annenin sık sık çocuğu bu konuda uyarması sonucunda davranış pekişmiştir. Çocuk eğitiminde temel yöntem olumsuz davranışları görmezden gelmek, olumlu davranışları ise manevi ödüllerle pekiştirmek olmalıdır.

Tırnak koparma davranışı her durumda patolojik 
olmayabilir. Genellikle sağlıklı çocuklarda geçicidir ve uzun sürmesi beklenmez. Kişinin herhangi bir uğraşısı olmadığında veya zor bir problemle uğraştığında daha fazla ortaya çıkar. Olgumuzda da benzer şekilde tırnak koparma davranışı daha çok stres anında ortaya çıkmakta, rahat olduğu zamanlarda ise görülmemektedir.

Erişkin dönemdeki sigara içme ve sakız çiğnemenin çocukluktaki tırnak koparmanın yerini tuttuğu düşünülmektedir. Tırnak koparma davranışı olan çocuklarda, dikkat eksikliği hiperaktivite bozukluğu,, karşı olma karşıt gelme bozukluğu ve ayrılık kaygısı bozukluğuna sık rastlanır. Ayrıca, enürezis, obsesif kompulsif bozukluk, major depresyon, mental retardasyon ve yaygın gelişimsel bozukluklar da eşlik edebilir. Tırnak koparma davranışı Tourette Sendromu olan ergen ve çocuklarda da görülmektedir (2).

Hesapçıŏlu ve ark. tarafindan yapılan çalışmada Tourette Sendromu ve kronik motor ya da vokal tik bozukluğu bulunan çocuk ve ergenlerde, tırnak koparanlarda tik bozukluğu görülme riskinin tırnak koparmayanlara göre 8,1 kat arttığı ve dikkat eksikliği ve hiperaktivite bozukluğu varlığı ile tırnak koparma arasında da anlamlı ilişki olduğu gösterilmiştir (5). Olgumuzda herhangi bir ek psikiyatrik hastalık saptanmamıştır.

Tirnak koparma enterobakterilerin ağız yoluna taşınmasına da sebep olur. Ciddi tırnak ısırma alveol y1kımı, maloklüzyon ve çene bozukluklarına sebep olabilir. Ayrıca tırnak koparma tırnak çevresindeki dokuya zarar verebilir, diş kökü hasarına ve enfeksiyona neden olabilir (2).

Nepal'de yapılan bir çalışmada çocukların \% 31,5'inde bağırsak paraziti saptanmış, parazit enfeksiyonu ile defekasyondan sonra sabun kullanmama, sandalet giymeme, tırnak koparma ve parmak emme davranış1 arasında anlamlı ilişki olduğu bildirilmiștir. Tırnak koparma alışkanlığı olan çocuklarda parazit oranı $(\% 56,5)$, tırnak koparma alışkanlığı olmayan çocuklara (\%13.6) göre anlamlı olarak yüksek saptanmıştır (6). Bizim olgumuzda dışkıda parazit incelenmiş sonuç negatif bulunmuştur.

Türkiye ve İtalya iş birliğinde yapılan bir çalışmada antibiyotiğe dirençli akut paronişi klinik ve sitolojik özellikleri incelenmiştir. Bu retrospektif araştırmada antibiyotiğe dirençli akut paronişi bulunan 58 hastanın \% 62'si çocuk ve ergenlerden oluşmakta olup, eşlik eden en sik faktörler parmak emme ve tırnak koparma olarak saptanmıştır. Bakteriyel, herpetik veya kandidal paronişilerle karşılaştırıldığında parmak emme ve tırnak koparmanın paronişiye daha fazla zemin hazırladığı bulunmuştur (7).

Tırnak koparma tedavilerinin çoğu davranışçı ve bilişsel davranış tedavisi seçeneklerine odaklanmakta, bu konuda sınırlı sayıda araştırma bulunmaktadır (1,8-11). Çocuklara model alarak öğrenme, alışkanlığg baskılama, ödüllendirme gibi bazı bilişsel davranışsal tekniklerle davranışlarını kontrol etme becerisi kazandırılmaktadır (2). Olgumuzda bilişsel davranışsal terapi uygulandı, ayrıca çocuğun kaygı ve stres etkenleri irdelendi. Annenin baskın rolü babaya aktarıldı. Babanın çocuklarına kural koyması ve çocukları ile olan iletişimini arttırması sağlandı. Ebeveynlerde farkındalık yaratılarak kardeşler arası ilişki düzenlendi ve yıkıcı rekabet yerine yapıcı rekabet sağlanması hedeflendi. Kardeşi ile arasındaki yaş farkı az olan çocukların, kendini diğer kardeşi ile daha fazla kıyaslayarak kıskançlık duygusunu daha hızlı ve daha yoğun bir şekilde hissedebilecekleri bilindiğinden (12), ebeveynlerde farkındalık yaratılarak kardeşler arası ilişki düzenlendi ve yıkıcı rekabet yerine yapıcı rekabet sağlanması hedeflendi.

Kastrasyon kayg1sı erkeklerde görülen, kendilerini kızlardan farklı kılan organlarını, "penisi” kaybetme ile ilgili korku olarak tanımlanmaktadır. Ülkemizde çocuklar yaramazlık yaptıklarında sık sık penislerini kaybetme ile tehdit edilirler: "Tutun bunu sünnet edelim” gibi. Sünnet ise ödipal dönemde hafiflemesi beklenen kastrasyon kaygısının canlı kalmasına neden olabilmektedir. (13) Olgumuzda da yaramazlık durumunda aile büyükleri tarafindan kızma ve korkutma amaçlı benzer söylemlerin yapıldığı anlaşıldı. Ağabeyinin sünnetini görmediği ve bu olaydan olumsuz etkilenmediği anlaşılan olgunun kaygısının aile büyükleri tarafından söylenilen 'yaramazlık yaparsan pipini keserim' gibi söylemler nedeniyle ortaya çıktığı belirlendi. Aile ile bu konunun ele alınması ve uygun söylemlerin desteklenmesi ile kastrasyon anksiyetesi giderildi.

Olgumuzda görüldüğü gibi, çocukları tehditlerle korkutmak yoğun endişelere yol açmaktadır. $\mathrm{Bu}$ da tırnak koparma gibi davranışları ortaya çıkarabilir. Aile ilișkilerinde anne ve babanın rolü çocuğun sosyal ve duygusal gelişimini etkilemektedir. Anne ve babanın aile dinamiklerinde etkin ve olumlu bir rol model olması hem kı hem erkek çocuklar için gereklidir. Ebeveynlerin davranıșları tutarlı ve kararlı olmalıdır. Çocuk eğitiminde pekiştireçler kullanılarak uygun davranışın kazandırılması hem davranış bozukluklarında tedavi edicidir hem de günlük alışkanlıkların kazanılmasında kullanılabilir. Eğitimde ceza vermek yerine olumlu manevi ve sözel pekiştireçler daha etkilidir.

\section{KAYNAKLAR}

1. Roberts S, O'Connor K, Bélanger C. Emotion regulation and other psychological models for bodyfocused repetitive behaviors. Clinical Psychology Review 2013;33:745-62.

2. Ghanizadeh A. Nail biting; etiology, consequences and management. Iran J Med Sci June 2011;36:73.

3. Coşkun A. Skinner ile Tolman kuramlarının karşılaştırılması ve bu kuramlar doğrultusunda kurulan bir okul. Pivolka 2005;19:15-19.

4. Snorrason I, Woods D. Nail picking disorder (onychotillomania): A case report. Journal of Anxiety Disorders 2014;(28):211-214.

5. Hesapçıŏglu S, Tural MK, Kandil S. Kronik tik bozukluklarında sosyodemografik, klinik özellikler ve risk etmenleri. Türk Psikiyatri Dergisi 2013;24(3):158-67.

6. Sah RB, Bhattarai S, Yadav S, R Baral, Jha N, Pokharel PK. A study of prevalence of intestinal parasites and associated risk factors among the 
school children of Itahari, Eastern Region of Nepal. Trop Parasitol 2013;3(2):140-144.

7. Durdu M, Ruocco V. Clinical and cytologic features of antibiotic-resistant acute paronychia. J Am Acad Dermatol 2014;70(1):120-6.

8. Koritzky G, Yechiam E. On the value of nonremovable reminders for behavior modification: An application to nail-biting (Onychophagia). Behav Modif 2011;35:511.

9. Moritz S, Treszl A, Rufer M. A randomized controlled trial of a novel self-help technique for impulse control disorders: A study on nail-biting. Behav Modif 2011;35:468.

10. Zawoyski AM, Bosch A, Vollmer TR, Walker SF. Evaluating the effects of matched and unmatched stimuli on nail biting in typically developing children. Behav Modif 2014;38:428.

11. Ghanizadeh A, Bazrafshan A, Firoozabadi A, Dehbozorgi G. Habit Reversal versus Object Manipulation Training for Treating Nail Biting: A Randomized Controlled Clinical Trial. Iran J Psychiatry 2013;8:2: 61-67.

12. Şipal F, Yeğengil C, Toka N. Okul öncesi dönemde aralarında yaş farkı olan ve ikiz kardeşler arasındaki kıskançlığın karşılaştırmalı olarak incelenmesi. Eğitim ve İnsani Bilimler Dergisi 2012;3: 5:55-68.

13. Öztürk OM. Ruh Sağlığı ve Bozuklukları. 7. basım, Ankara, Hekimler Yayın Birliği 1997;77-8. 